\title{
Associations between program outcomes and adherence to Social Cognitive Theory tasks: process evaluation of the SHED-IT community weight loss trial for men
}

\author{
Philip J Morgan ${ }^{1,2^{*}}$, Hayley A Scott ${ }^{1,2}$, Myles D Young ${ }^{1,2}$, Ronald C Plotnikoff ${ }^{1,2}$, Clare E Collins ${ }^{1,3}$
} and Robin Callister ${ }^{1,4}$

\begin{abstract}
Background: Despite rising international rates of obesity, men remain reluctant to participate in weight loss research. There is a lack of evidence to guide the development of effective weight loss interventions that engage men. The objective of this study was to provide a comprehensive process evaluation of the SHED-IT (Self-Help, Exercise and Diet using Information Technology) weight loss program for men, as delivered in the SHED-IT community weight loss trial, and to identify key components associated with success.
\end{abstract}

Methods: In an assessor-blinded randomised controlled trial, 159 overweight and obese men (BMI 25.0-40.0 kg/m²) were randomised to one of two gender-tailored weight loss interventions with no face-to-face contact, or a control group. The interventions were informed by Bandura's Social Cognitive Theory (SCT) with men encouraged to complete a Support Book containing SCT-based tasks including goal setting, reward setting, creation of social support strategies and self-monitoring of: i) weight, ii) physical activity, and iii) diet. At post-test, compliance with SCT tasks was examined and men also completed a process evaluation questionnaire.

Results: Both SHED-IT intervention groups demonstrated greater weight loss during the intervention compared to the control, with no difference between intervention groups. Most men engaged with the SCT tasks although compliance declined over time and utilisation of social support networks and reward selection was poor. In a multiple regression model, the number of goals set $(\beta[95 \% \mathrm{Cl}]=-0.3[-0.6,-0.1], \mathrm{p}=0.01)$ and the number of weight records documented $(\beta[95 \% \mathrm{Cl}]=-0.2[-0.4,-0.0], p=0.03)$ independently predicted weight loss. The process evaluation indicated that men found the programs to be supportive, enjoyable and beneficial.

Conclusions: This process evaluation provides valuable information to inform the development of obesity treatment strategies that engage men. Future studies with men should include a strong focus on self-monitoring and goal setting to enhance behaviour change and improve treatment effects.

Trial registration: Australian New Zealand Clinical Trials Registry ACTRN12610000699066.

Keywords: Social cognitive theory, Men, Obesity, Online, Process evaluation, Weight loss

\footnotetext{
* Correspondence: Philip.Morgan@newcastle.edu.au

${ }^{1}$ Priority Research Centre in Physical Activity and Nutrition, The University of

Newcastle, Callaghan 2308, NSW, Australia

${ }^{2}$ School of Education, Faculty of Education and Arts, The University of

Newcastle, Callaghan 2308, NSW, Australia

Full list of author information is available at the end of the article
} 


\section{Background}

Obesity is an increasingly prevalent global health problem [1]. Obesity more than triples the risk of developing type 2 diabetes, gall bladder disease and sleep apnoea, and doubles the risk of heart disease, hypertension and asthma $[2,3]$. This is particularly concerning for males who exhibit a visceral abdominal pattern of obesity, which further increases the risk of developing obesity-related chronic diseases [2]. Despite the need for weight management, men are less likely to perceive themselves as overweight [4] or to participate in weight loss interventions or research [5]. This may arise from a lack of appeal of traditional weight loss programs and/or reduced motivation after previous failed weight loss attempts [6]. Previous studies indicate that face-to-face weight loss programs, particularly groupbased programs, do not appeal to men [5-8]. Consequently, there is a need to develop weight loss programs targeted to men's physical and psychological profile $[9,10]$. Men also report preferences for convenient programs that include personalised feedback, people they can relate to (particularly other men), the use of humour and minimal disruption to their current lifestyle $[6,8,11]$.

Currently, there is a lack of evidence to guide the development of effective weight loss interventions for men. Recent systematic reviews have clearly demonstrated that men are consistently under-represented in weight loss research [5,9]. As such, many of the current recommendations provided to men attempting weight loss are based on trials that were predominantly conducted with women. A recent systematic review of male-only weight loss studies documented the success of gender-targeted approaches, but noted more high-quality studies are required to improve understanding of how to successfully engage men with effective weight loss programs [9]. Process evaluation of such studies is an integral component of intervention research as it establishes the quality of the intervention and informs the design and implementation of future trials [12]. Process evaluation may examine participants' views of the program, whether the program was implemented as intended and the effectiveness of individual program components in relation to study outcomes [12]. As there is limited evidence regarding effective weight loss interventions for men [5,9], process evaluation of male-only trials is essential to determine (i) which treatment modalities are feasible and acceptable to men, and (ii) which intervention components are associated with successful treatment outcomes in men.

We developed a male-only weight loss program called the SHED-IT (Self-Help, Exercise, and Diet using Information Technology) Program that involved no face-toface contact and was tailored for men. This program was successfully tested in a pilot study with University staff and students $[10,11,13-15]$ and was subsequently refined and tested in an effectiveness trial with a large community sample of overweight and obese men [16,17]. Although both trials tested the SHED-IT program, important intervention changes were made between trials. For example, for the current trial, the face-to-face session was removed from the intervention and replaced with a DVD to improve scalability. In addition, Bandura's Social Cognitive Theory (SCT) was more rigorously operationalised in the current intervention, with participants completing a newly developed weight loss Support Book containing SCT tasks. The study protocol [16] and outcomes [17] of the current trial have been reported elsewhere. The SHED-IT program targeted behaviour change mediators outlined in Bandura's SCT [18], which provides a framework for changing an individual's cognitions in order to improve adherence with optional behaviours. Men must value the outcome (i.e. weight loss) if they are to make changes to dietary and exercise behaviours. They must believe weight loss will occur by making these changes and that they have the confidence, knowledge and skills required to implement these changes.

In the current study, we present the findings of a comprehensive process evaluation 3-months post-intervention of the SHED-IT community weight loss randomised controlled trial (RCT) [16]. Specifically, we investigated the following three research aims:

1) To report participant engagement with SCT-based program tasks including goal setting, reward setting, social support and self-monitoring of: i) weight, ii) physical activity, and iii) dietary intake;

2) To examine the association between compliance with SCT-based tasks and weight loss;

3) To examine men's perceptions of the quality of the SHED-IT program and its impact on their weight as well as their knowledge and skills about weight loss.

\section{Methods}

\section{Study design}

The SHED-IT community trial has been described in detail previously [16,17]. Briefly, this assessor-blinded RCT included a community sample of overweight and obese men (BMI 25.0-40.0 $\mathrm{kg} / \mathrm{m}^{2}$ ) from the Hunter region of New South Wales, Australia. Participants were randomly allocated to one of three study arms: i) SHED-IT Resources; ii) SHED-IT Online, or iii) a wait-list control group. This study was approved by the Human Research Ethics Committee, University of Newcastle and all subjects provided written informed consent. The trial was registered with the Australian New Zealand Clinical Trials Registry, Number ACTRN12610000699066.

\section{Intervention descriptions}

The SHED-IT interventions were based on SCT, in which Bandura proposes that behaviour change is influenced by 
attributes of the behaviour itself, personal factors and environmental factors [18]. In order to target the key behaviour change constructs outlined in SCT, the SHED-IT interventions first aimed to educate participants about the physical, social, and self-evaluative (i.e. personal) benefits of weight loss through increased physical activity and healthy eating. In addition, the resources were designed to increase participants' self-efficacy for performing these behaviours and assist them to develop the self-regulatory skills needed to sustain the behaviours over time and in the face of potential barriers. These self-regulatory behaviours include goal setting, self-monitoring and reward provision [19]. Finally, given the importance of sociostructural facilitators in establishing long-term behaviour change, the SHED-IT resources were designed to help men engage with their social networks and establish helpful social support strategies [18]. Both the $R e$ sources and Online SHED-IT interventions included the same core components and were based on the same theoretical constructs. Men were instructed to complete all program tasks for 3-months which, excluding data collection visits, were completed without face-to-face contact.

\section{SHED-IT Resources intervention}

Men randomised to the Resources group received a resource package containing the 'SHED-IT Weight Loss Handbook for Blokes', a 25-minute 'Weight Loss DVD for Blokes', a kilojoule counter book, a pedometer and a tape measure. These resources focused on nine key weight loss messages: 1) Read food labels, 2) Keep a healthy lifestyle diary, 3) Reduce kilojoule-dense snacks, 4) Be prepared, 5) Every step counts, 6) Reduce your sitting time, 7) Surf the urge (in reference to resisting the urge to snack unnecessarily), 8) Reduce your portion sizes, and 9) Don't drink your kilojoules.

In addition to these resources, men also received the "SHED-IT Weight Loss Support Book for Blokes", henceforth referred to as the Support Book, which included the following six sections:

\section{i) Calculating kilojoule output}

ii) Weight and waist record charts: Participants updated charts weekly.

iii) Pedometer diary: Participants monitored step counts four days each week, calculated the average, and plotted the weekly average on a chart.

iv) Goal setting: Participants were advised to set three goals monthly, one for weight loss, one for physical activity and one for dietary intake. Instructions for setting SMART goals (i.e. Specific, Measureable, Attractive, Realistic and Time-targeted) and examples were provided. Men were also instructed to mark off each achieved goal and record a reward they would receive at the end of each month if they successfully achieved all three goals.

v) Social support strategies: Men were instructed to record one or two social support strategies each month. Instructions and examples were provided.

vi) Healthy lifestyle diary: Instructions were provided for recording dietary intake and exercise participation on four days of each week for the 3-month intervention. This was paper-based and included space to calculate whether the daily kilojoule target for weight loss was achieved.

\section{SHED-IT Online intervention}

Those randomised to the Online group received a website user guide in addition to the resource package described above. The user guide included information on using the freely available Calorie King ${ }^{\mathrm{Tm}}$ (Australia) website (http:// www.calorieking.com.au) and instructed participants to record dietary intake and exercise online for four days per week, in place of the paper-based diary completed by the Resources group. Participants also had the option of selfmonitoring their weight, waist and pedometer steps on the website rather than the Support Book, if they chose. Contingent on diary completion, research assistants provided men with seven individualised feedback emails based on their online food and exercise diary entries. These were provided weekly during the first month, fortnightly during the second month and once during the third month.

\section{Data collection}

Men were measured at baseline, 3 months (immediate post-intervention) and 6 months (3-month follow-up). All measurements were performed by trained research assistants who were blinded to group allocation.

\section{Measurement of anthropometrics, demographics and behaviours}

Body weight (CH-150kp, A\&D Mercury Pty Ltd, Australia) and height were measured, and Body Mass Index (BMI) was calculated. Waist circumference was measured at the umbilicus and the largest circumference between the umbilicus and lower costal border [20] (KDSF10-02, KDS Corporation, Osaka, Japan), and body fat $(\mathrm{kg})$ was determined by bio-impedance analysis (InBody720, Biospace Co., Ltd, Seoul, Korea) [21]. Age and socioeconomic status [22] were determined by questionnaire. Dietary intake was measured using the validated Australian Eating Survey [23], while physical activity levels were objectively measured via seven days of pedometry with Yamax digiwalker SW200 pedometers (Yamax Digi-Walker SW200, Kunamoto City, Japan).

\section{Program compliance measures}

Compliance with SCT-based tasks was quantified by examining adherence to each of the six Support Book 
components during the 3-month intervention phase. Specifically, this comprised self-monitoring of weight, waist circumference and pedometer step counts; setting of goals, rewards, and social support strategies; and monitoring dietary intake and exercise participation. Compliance with each Support Book component was defined as recording each component at least $80 \%$ of recommended reporting times. For example, compliance with monitoring waist circumference was defined as weekly recording of waist circumference measurements at least 11 times over the 3month (13-week) period. This cut-off was chosen based on data from the SHED-IT pilot study [13], where men who completed $80 \%$ of weight entries and $80 \%$ of the food and exercise diary recommendations demonstrated significantly greater program outcomes compared to those that did not. Participants were advised to set SMART goals, with examples provided, such as "this month, I will go for a half-hour walk around the neighbourhood, three times per week". Quality social support strategies were defined as engaging a person from one's social support network to participate in a supportive activity that would aid in successful completion of the SHED-IT program requirements.

A project-specific process evaluation questionnaire, adapted from an instrument used in previous research [11], was completed at the 6-month assessments. This questionnaire measured perceptions of the SHED-IT program in general; satisfaction with the program resources including the DVD, the Handbook and the Support Book, and the effect of the program on the people around them. The Online group completed additional questions regarding perceptions of the Calorie King website and personalised feedback reports.

\section{Statistical analysis}

Data were analysed using Statistical Package for the Social Sciences (SPSS version 20.0 software; SPSS, Chicago, IL, USA) and are reported as mean (standard deviation), median (interquartile range) or the percentage of participants for each specified variable. For continuous variables, groups were compared using analysis of variance (ANOVA) with Bonferroni post-hoc testing. Proportions of subjects recording each Support Book component were examined using Pearson's chi-squared test (Aim 1). The correlation between change in selected outcomes (e.g. weight, waist circumference, physical activity) and engagement with each Support Book component (i.e. goal setting and rewards, social support, monitoring of weight and pedometer steps, dietary intake and exercise participation) was assessed using the Spearman rank test $\left(\mathrm{r}_{\mathrm{s}}\right.$ ) (Aim 2). Backward stepwise regression was performed using Stata (Intercolled Stata version 11.2, Stata Corporation, College Station, TX, USA) to determine the independent effect completing each Support Book component had on weight change $(\mathrm{kg})$ (Aim 2). These analyses were adjusted for age and socio- economic status (SES), which are known to interact with weight [24] and treatment outcomes in previous weight loss trials with men $[25,26]$. Intervention group was also adjusted for in the analyses. In addition, the robust variance estimator was applied to account for the data being skewed. As records for waist circumference measurement and exercise participation were highly correlated with records for weight measurement and dietary intake respectively, they were not included in the regression model. Process evaluation questions were analysed by independent samples t-tests to determine the main effect of intervention allocation (i.e. Online vs. Resources) on participants' perceptions of the SHED-IT program (Aim 3). P-values $<0.05$ were considered statistically significant for all analyses (Aim 3).

\section{Results}

\section{Participant characteristics}

The high appeal of a male-only weight loss program of this nature was demonstrated by the recruitment of 159 men from more than 600 enquiries within a one-week period. A total of 53 men were randomised to the Online group, 10 of which withdrew [17] and 11 did not return their Support Book, leaving 32 included in the analysis of program compliance. For the Resources group, 54 men were randomised, 11 withdrew [17], and eight did not return their Support Book, totalling 35 men included in the compliance analysis. For those included in the analysis of compliance, more men of a high SES completed the Online program and returned their Support Book compared to the Resources program. However as mentioned previously, SES was adjusted for in the analyses, where significant.

At baseline, these participants $(n=67)$ had a mean (SD) age of 47.3 (10.9) years, BMI of $32.6(13.5) \mathrm{kg} / \mathrm{m}^{2}$, walked 6950 (2962) steps per day and consumed 11547 (3496) kJ per day. The only significant difference between groups at baseline was SES, with more participants in the Resources group living in higher socio-economic areas than men in the Online group. Additional information on participants' baseline characteristics can be found in Additional file 1: Table S1.

As previously reported, after 6 months, weight was significantly reduced $(\mathrm{p}<0.001)$ in both the Online group $(-4.7 \mathrm{~kg}, 95 \%$ CI $-6.1,-3.2)$ and Resources group (-3.7 kg, $95 \%$ CI $-4.9,-2.5)$ relative to the control group $(-0.5 \mathrm{~kg}$, 95\% CI $-1.4,0.4)$, with no significant difference between intervention groups $(p>0.05)$ [17]. There was also a significant decrease in energy intake in both the Online (-1673 kJ/day, 95\% CI -2268, -1078) and Resources $(-1190 \mathrm{~kJ} /$ day, 95\% CI -1924, -456) groups. In addition, significant increases in physical activity were observed for the Online group (1575 steps/day, 95\% CI 753, 2397) and Resources group (1586 steps/day, 95\% CI (796, 2376). As 
with weight, the differences between interventions were not significant for these outcomes ( $p>0.05$ for both) [17].

\section{Engagement with SCT-based program tasks}

Table 1 shows the Online and Resources groups had similar levels of compliance with recording goals and social support strategies, and monitoring weight, waist circumference and dietary intake. Approximately half of the men set weight, exercise and nutrition-related goals during the 3-month program, with more than half of these reporting having achieved these goals. Very few participants recorded social support strategies, with compliance decreasing from month one $(44 \%)$ to month three $(25 \%)$. The proportion of men who were compliant with monitoring their weight ( $63 \%$ vs. $50 \%, p=0.31)$, waist circumference ( $56 \%$ vs. $43 \%, p=0.27$ ), pedometer steps $(45 \%$ vs. $49 \%, p=0.78)$ and dietary intake $(63 \%$ vs. $50 \%, p=0.31$ ) was similar for the Online and Resources groups. However, the Online group were more compliant with monitoring their exercise participation than the Resources group ( $41 \%$ vs. $18 \%, \mathrm{p}=0.046)$.

As there were essentially no differences between intervention groups for program engagement, or outcomes achieved [17], data were pooled for clarity. Table 2 shows that $51 \%$ of all weight loss goals set aimed for the recommended $0.5-1.0 \mathrm{~kg}$ weight loss per week, although $24 \%$ of goals aimed for $>1 \mathrm{~kg}$ of weight loss per week. Approximately $60 \%$ of all exercise goals aimed to increase walking or reach a predetermined pedometer step target, while bike riding and strength training were also popular. The proportion of SMART exercise goals decreased significantly during the third month of the program, but on average $80 \%$ of all goals were SMART. Nutrition goals were recorded approximately half of the time. However, only $56 \%$ of these goals were SMART and decreased significantly throughout the program. The most popular nutrition goals related to reducing intake of 'junk food' (e.g. chips, pies, soft drink) and increasing intake of fruits and vegetables. Documenting rewards for goal achievement was low, with less than one-third of men recording goal achievement in any given month. Approximately half of rewards listed related to a night out for dinner or alcohol.

Table 3 illustrates that many men did not record strategies to engage their social support networks. Only $43 \%$ of men recorded at least one social support strategy during the first month of the program, which fell to only $21 \%$ during the third month. In addition, men did not appear to grasp the concept of social support, with $34 \%$ of the men naming themselves as their support person rather than their actual support network. Thus, only $34 \%$ of men recorded 'quality' social support strategies in the first month and only $11 \%$ during the third month. Overall, the most popular person men recorded in social support strategies was their partner or wife, which was expected as $86 \%$ of men in the study were either married or in a defacto relationship. The most popular type of lifestyle supports were physical activity-based such as walking, sports or attending the gymnasium. The most popular activities linked to wives/partners was walking, supporting their participation in the SHED-IT program and avoiding the purchase of 'junk food'. In contrast, the most popular activities men reported they would undertake with their children or grandchildren were walking and bike riding. Friends were most commonly enlisted to participate in sports, attend the gymnasium and assist with reducing alcohol intake. For additional detail on the link between social support strategies and the person providing the support, see Additional file 1: Table S2.

\section{Association between compliance to SCT-based tasks and study outcomes}

Table 4 presents correlations between anthropometric, dietary and physical activity outcomes, and compliance with SHED-IT program SCT-based tasks. There were strong and consistent inverse correlations between program compliance and changes to body composition, whereby those who were more compliant with recording SCT-based tasks also demonstrated greater reductions in weight, waist circumference and body fat. Additionally, there was a positive correlation between compliance with monitoring dietary intake and physical activity, as well as with changes to weight, waist circumference, fat mass and dietary fat intake.

Table 5 presents results for the associations between weight loss and Support Book compliance by utilising a multiple linear regression model. Inter-correlations between the Support Book components ranged from $r=$ 0.21 (food diary/rewards) to $\mathrm{r}=0.68$ (goals/social support) (Additional file 1: Table S3). The number of goals set $(\beta$-coefficient $[95 \% \mathrm{CI}]=-0.3[-0.6,-0.1], p=0.01)$ and the number of weight records documented ( $\beta$-coefficient $[95 \% \mathrm{CI}]=-0.21[-0.39,-0.02], p=0.03)$ were independently associated with weight loss, whereby each additional goal set and weight measurement recorded was associated with an increased weight loss of $0.32 \mathrm{~kg}$ and $0.21 \mathrm{~kg}$, respectively $\left(\mathrm{R}^{2}=0.37, p<0.001\right)$. This equates to an additional $2.9 \mathrm{~kg}$ and $2.7 \mathrm{~kg}$ weight loss respectively, for those who set all their goals and monitored their weight weekly, compared to those who did not engage in these activities. Age, SES and intervention group were not significant predictors of weight change in this model ( $p>0.05$ for each).

\section{Participant perceptions of the SHED-IT program}

A total of 38 men from the Online group (88.4\%) and 37 men from the Resources group (86.0\%) completed the process evaluation questionnaire at 6-months (Table 6). 
Table 1 Engagement with program components using the Support Book

\begin{tabular}{lll}
\hline & $\begin{array}{l}\text { Online } \\
(n=32)\end{array}$ & $\begin{array}{l}\text { Resources } \\
(n=35)\end{array}$ \\
\hline
\end{tabular}

Goal Setting (\%) ${ }^{\mathrm{a}}$

Month 1

Weight Goal

Achieved $^{b}$

PA Goal

Achieved $^{b}$

Nutrition Goal

Achieved $^{b}$

Reward

Month 2

Weight Goal

Achieved $^{b}$

PA Goal

Achieved $^{b}$

Nutrition Goal

Achieved $^{b}$

Reward

Month 3

Weight Goal

Achieved $^{\mathbf{b}}$

PA Goal

Achieved $^{b}$

Nutrition Goal

Achieved $^{b}$

Reward

Social Support (\%)

Month 1

Two Strategies Recorded

One Strategy Recorded

No Strategies Recorded

Month 2

Two Strategies Recorded

One Strategy Recorded

No Strategies Recorded

Month 3

Two Strategies Recorded

One Strategy Recorded

No Strategies Recorded

Calculating kJ Output (\%)

Self-Monitoring ${ }^{c}$

Weight

Waist Circumference

Pedometer Steps

$\begin{array}{lll}59.4 & 61.8 & 0.84\end{array}$

$\begin{array}{lll}63.1 & 66.7 & 0.76\end{array}$

$\begin{array}{lll}56.3 & 61.8 & 0.65\end{array}$

$\begin{array}{lll}72.1 & 71.4 & 0.77\end{array}$

$\begin{array}{lll}53.1 & 61.8 & 0.48\end{array}$

$\begin{array}{lll}76.5 & 71.4 & 0.77\end{array}$

$\begin{array}{lll}25.0 & 35.3 & 0.36\end{array}$

$\begin{array}{lll}53.1 & 44.1 \quad 0.46\end{array}$

$\begin{array}{lll}76.5 & 66.7 & 0.34\end{array}$

$\begin{array}{lll}50.0 & 41.2 & 0.47\end{array}$

$81.2 \quad 78.6 \quad 0.49$

$\begin{array}{lll}50.0 & 41.2 & 0.47\end{array}$

$81.2 \quad 78.6 \quad 0.49$

$\begin{array}{lll}25.0 & 23.5 & 0.89\end{array}$

$\begin{array}{lll}50.0 & 41.2 \quad 0.47\end{array}$

$\begin{array}{lll}43.8 & 64.3 \quad 0.66\end{array}$

$\begin{array}{lll}46.9 & 41.2 & 0.64\end{array}$

$\begin{array}{lll}59.9 & 57.0 \quad 0.67\end{array}$

$\begin{array}{lll}43.8 & 38.2 & 0.65\end{array}$

$\begin{array}{lll}57.1 & 61.5 & 0.89\end{array}$

$\begin{array}{lll}15.6 & 17.6 & 0.83\end{array}$

$\begin{array}{lll}37.5 & 31.4 & 0.71\end{array}$

$6.3 \quad 11.4$

$56.3 \quad 56.7$

$25.0 \quad 20.0$

$3.1 \quad 2.9$

$71.9 \quad 77.1$

$18.8 \quad 14.3$

6.30

$75.0 \quad 85.7$

$77.4 \quad 82.9$

$11(3,13) \quad 10(4,13) \quad 1.00$

$7(1,12) \quad 10(1,12) \quad 0.89$

$6(0,12) \quad 10(0,12) \quad 0.66$
Table 1 Engagement with program components using the Support Book (Continued)

\begin{tabular}{llll}
\hline Compliance With Self-Monitoring $^{\mathbf{d}}$ & & & \\
Weight & 62.5 & 50.0 & 0.31 \\
Waist Circumference & 56.3 & 42.9 & 0.27 \\
Pedometer Steps & 45.2 & 48.6 & 0.78 \\
Dietary Intake & 63.0 & 50.0 & 0.31 \\
Exercise Participation & 40.7 & 17.6 & $\mathbf{0 . 0 4 6}$
\end{tabular}

${ }^{a}$ Recorded as \% the percentage of participants completing the specified Support Book component.

${ }^{\mathrm{b}}$ Reported as the percentage of participants achieving the specified goal.

'Median (IQR) number of weekly records made during the 3-month study (out of a possible 13).

${ }^{\mathrm{d}}$ Proportion of participants regarded as compliant with self-monitoring.

Compliance was defined as completing the specified Support Book component $\geq 80 \%$ of the time.

${ }^{\mathrm{e}}$ Bolded $p$ value is statistically significant $(p<0.05)$.

Overall, participants were very satisfied with the SHEDIT program. Men found the DVD and other weight loss resources engaging and enjoyable, and agreed that the program had positive effects on those around them. Although both groups indicated that the program provided them with sufficient support for weight loss, the Online group reported significantly stronger agreement than the Resources group. Most men reported reading the Weight Loss Handbook for Blokes once (26\%) or 2-3 times (57\%), with $91 \%$ indicating that the length of the Handbook was appropriate. Most participants (93\%) felt the 25-minute DVD was an appropriate length. Sixty-five percent of men reported watching the DVD once, while $34 \%$ watched it more than once.

In the Online group, the men reported that the CalorieKing ${ }^{\text {Th }}$ website was useful for weight loss and was relatively easy to understand. This group also indicated that the feedback reports were helpful and assisted them in losing weight. Two-thirds of participants reported always reading their email feedback reports, while $11 \%$ read them some of the time, $14 \%$ half the time or most of the time and $6 \%$ reported to have never read them.

Most participants reported using at least five of the nine SHED-IT weight loss tips. Overall, the most commonly used weight loss tips were 'read food labels' ( $81 \%$ of participants), 'reduce your portion sizes' ( $81 \%$ of participants) and 'reduce kJ dense snacks' (73\% of participants). Resources group compliers were more likely than non-compliers to use the tip 'keep a healthy lifestyle diary' $(\mathrm{p}=0.02)$, while Online group compliers were more likely to use the tip 'surf the urge' $(\mathrm{p}=0.01)$. For more information on the SHED-IT weight loss tip results, see Additional file 1: Table S4.

\section{Discussion}

The overall aim of this paper was to conduct a comprehensive process evaluation of the previously established 
Table 2 Goals and rewards recorded during the SHED-IT program $(n=66)$

\begin{tabular}{|c|c|c|c|c|c|}
\hline & Overall & Month 1 & Month 2 & Month 3 & $P$-value ${ }^{c}$ \\
\hline \multicolumn{6}{|l|}{ Weight Goals } \\
\hline Recorded & 51.5 & 60.6 & 48.5 & 45.5 & 0.18 \\
\hline \multicolumn{6}{|l|}{ What? } \\
\hline$<0.5 \mathrm{~kg} /$ week & 20.6 & 15.0 & 21.9 & 26.7 & \multirow[t]{4}{*}{0.30} \\
\hline $0.5-1 \mathrm{~kg} /$ week & 51.0 & 52.5 & 53.1 & 46.7 & \\
\hline$>1 \mathrm{~kg} /$ week & 23.5 & 27.5 & 12.5 & 10.0 & \\
\hline Other & 4.9 & 0 & 6.3 & 10.0 & \\
\hline SMART ${ }^{\mathrm{a}}$ & 96.1 & 100.0 & 93.8 & 93.2 & 0.08 \\
\hline \multicolumn{6}{|l|}{ Exercise Goals } \\
\hline Recorded & 49.5 & 59.1 & 45.5 & 43.9 & 0.16 \\
\hline \multicolumn{6}{|l|}{ What? } \\
\hline Pedometer Count & 31.9 & 31.0 & 40.0 & 25.6 & \multirow[t]{6}{*}{0.26} \\
\hline Walk & 25.9 & 33.3 & 20.0 & 23.1 & \\
\hline Bike Ride & 13.8 & 14.3 & 11.4 & 15.4 & \\
\hline Gymnasium/Strength Training & 13.8 & 7.1 & 14.3 & 20.5 & \\
\hline Run/Jog & 2.6 & 0 & 0 & 7.7 & \\
\hline Other & 12.1 & 14.3 & 14.3 & 7.7 & \\
\hline SMART ${ }^{\mathrm{a}}$ & 79.6 & 84.6 & 83.3 & 65.6 & 0.03 \\
\hline \multicolumn{6}{|l|}{ Nutrition Goals } \\
\hline Recorded & 48.0 & 57.6 & 45.5 & 40.9 & 0.14 \\
\hline \multicolumn{6}{|l|}{ What? } \\
\hline Junk Food ${ }^{b}$ & 18.7 & 32.0 & 5.7 & 12.5 & \\
\hline FruitNegetables & 11.1 & 6.0 & 17.1 & 12.5 & \multirow[t]{8}{*}{0.15} \\
\hline Kilojoule Target & 9.4 & 8.0 & 8.6 & 12.5 & \\
\hline Water & 8.5 & 12.0 & 2.9 & 9.4 & \\
\hline Portion Size & 8.5 & 6.0 & 8.6 & 12.5 & \\
\hline Alcohol & 7.7 & 4.0 & 11.4 & 9.4 & \\
\hline Caffeine & 6.8 & 8.0 & 8.6 & 3.1 & \\
\hline Breakfast & 5.1 & 8.0 & 5.7 & 0 & \\
\hline Other & 23.9 & 16.0 & 31.4 & 28.1 & \\
\hline SMART ${ }^{\mathrm{a}}$ & 55.8 & 73.6 & 46.6 & 40.8 & $<0.01$ \\
\hline \multicolumn{6}{|l|}{ Reward } \\
\hline Recorded & 23.7 & 30.3 & 24.2 & 16.7 & 0.18 \\
\hline \multicolumn{6}{|l|}{ What? } \\
\hline Dinner at a Restaurant & 27.7 & 25.0 & 43.8 & 9.1 & \multirow[t]{6}{*}{0.66} \\
\hline Alcohol/"Night Out" & 21.3 & 30.0 & 12.5 & 18.2 & \\
\hline Special Purchase (e.g. golf driver, concert tickets) & 17.0 & 20.0 & 12.5 & 18.2 & \\
\hline New Clothes & 10.6 & 5.0 & 12.5 & 18.2 & \\
\hline Achieving Goals/Feeling Better & 4.3 & 5.0 & 0 & 9.1 & \\
\hline Other & 19.1 & 15.0 & 18.8 & 27.3 & \\
\hline
\end{tabular}

Data presented as \%, the percentage of participants recording the specified variable. Results were combined for Online and Resources groups. $P$-value represents

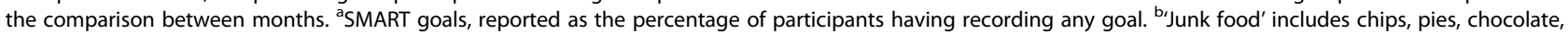
cakes, biscuits, lollies, soft drink and 'fast food'. 'Bolded $p$ value is statistically significant $(p<0.05)$. 
Table 3 Social support strategies recorded during the SHED-IT program $(n=67)$

\begin{tabular}{|c|c|c|c|c|c|}
\hline & Overall & Month 1 & Month 2 & Month 3 & $P$-value ${ }^{\mathrm{b}}$ \\
\hline \multicolumn{6}{|l|}{ Strategies Recorded } \\
\hline Two & 23.9 & 32.8 & 22.4 & 16.4 & \multirow[t]{3}{*}{0.04} \\
\hline One & 6.0 & 10.4 & 3.0 & 4.5 & \\
\hline None & 70.1 & 56.7 & 74.6 & 79.1 & \\
\hline \multicolumn{6}{|l|}{ Quality Strategies Recorded } \\
\hline Two & 12.9 & 25.4 & 7.5 & 6.0 & \multirow[t]{3}{*}{$<0.01$} \\
\hline One & 8.0 & 9.0 & 10.4 & 4.5 & \\
\hline None & 79.1 & 65.7 & 82.1 & 89.6 & \\
\hline \multicolumn{6}{|l|}{ Who? ${ }^{\mathrm{a}}$} \\
\hline Partner/Wife & 36.5 & 47.3 & 27.3 & 25.9 & \multirow[t]{6}{*}{0.02} \\
\hline Himself & 33.9 & 14.5 & 48.5 & 55.6 & \\
\hline Child(ren)/Grandchild(ren) & 15.7 & 20.0 & 15.2 & 7.4 & \\
\hline Friend(s) & 6.1 & 9.1 & 3.0 & 3.7 & \\
\hline Work Colleague(s) & 6.1 & 5.5 & 6.1 & 7.4 & \\
\hline $\operatorname{Dog}(s)$ & 1.7 & 3.7 & 0 & 0 & \\
\hline \multicolumn{6}{|l|}{ What? ${ }^{\mathrm{a}}$} \\
\hline Walk & 34.8 & 40.4 & 30.3 & 29.6 & \multirow[t]{7}{*}{0.51} \\
\hline Sport/Gymnasium & 12.5 & 7.7 & 18.2 & 14.8 & \\
\hline Avoid Purchasing Unhealthy /Fast Food & 11.6 & 15.4 & 6.1 & 11.1 & \\
\hline Alcohol Intake & 7.1 & 11.5 & 3.0 & 3.7 & \\
\hline Participate In/Support SHED-IT Program & 5.4 & 3.8 & 6.1 & 7.4 & \\
\hline Ride Bike & 2.7 & 3.8 & 3.0 & 0 & \\
\hline Other & 25.9 & 17.3 & 33.3 & 33.3 & \\
\hline
\end{tabular}

Data presented as \%, the percentage of participants recording the specified variable. Results were combined for Online and Resources groups. Quality social support strategy defined as engaging a person other than themselves in a supportive activity. $P$-value represents the comparison between each month.

${ }^{a}$ Reported as the percentage of the total number of social support strategies recorded. ${ }^{\mathrm{b}}$ Bolded $p$ value is statistically significant $(p<0.05)$.

successful SHED-IT weight loss program for men. Our findings indicate that most men undertook SCT-based tasks including goal setting and monitoring of weight, physical activity and dietary intake. However, utilisation of social support networks and reward selection was poor. Of the SCT-based tasks, the most critical for success were goal setting and weekly weight monitoring, which were independently associated with weight loss. The Online and Resources versions of the SHED-IT program performed equally well, with no differences in

Table 4 Correlation between change in selected outcomes and Support Book engagement

\begin{tabular}{|c|c|c|c|c|c|c|c|c|c|c|}
\hline & Goals & $\begin{array}{l}\text { SMART } \\
\text { goals }\end{array}$ & $\begin{array}{l}\text { Exercise } \\
\text { goals }\end{array}$ & $\begin{array}{l}\text { Nutrition } \\
\text { goals }\end{array}$ & Rewards & $\begin{array}{l}\text { Social support } \\
\text { strategies }\end{array}$ & $\begin{array}{l}\text { Weight } \\
\text { record }\end{array}$ & $\begin{array}{l}\text { Pedometer } \\
\text { record }\end{array}$ & $\begin{array}{l}\text { Exercise } \\
\text { diary entries }\end{array}$ & $\begin{array}{l}\text { Food diary } \\
\text { entries }\end{array}$ \\
\hline Weight (kg) & $-0.47^{* * *}$ & $-0.49 * * *$ & $-0.47^{* * *}$ & $-0.47^{* * *}$ & $-0.33^{* *}$ & $-0.44^{* *}$ & $-0.51^{* * *}$ & $-0.36^{* *}$ & $-0.47^{* * *}$ & $-0.46^{* * *}$ \\
\hline $\begin{array}{l}\text { Waist Circumference } \\
(\mathrm{cm})\end{array}$ & $-0.54^{* * *}$ & $-0.54^{* * *}$ & $-0.55^{* * *}$ & $-0.50^{* * *}$ & $-0.38^{* *}$ & $-0.38^{* *}$ & $-0.46^{* * *}$ & $-0.36^{* *}$ & $-0.48^{* * *}$ & $-0.46^{* * *}$ \\
\hline Fat Mass (kg) & $-0.42^{* * *}$ & $-0.46^{* * *}$ & $-0.42^{* *}$ & $-0.42^{* * *}$ & $-0.27^{*}$ & $-0.32^{* *}$ & $-0.45^{* * *}$ & $-0.39^{* *}$ & $-0.46^{* * *}$ & $-0.45^{* * *}$ \\
\hline Energy (kJ) & 0.09 & 0.04 & 0.10 & 0.06 & 0.08 & 0.10 & -0.09 & -0.16 & -0.02 & -0.11 \\
\hline Total Fat (\%) & -0.04 & $-0.26^{*}$ & $-0.25^{*}$ & $-0.25^{*}$ & -0.16 & -0.10 & -0.19 & -0.13 & $-0.35^{* *}$ & $-0.34^{* *}$ \\
\hline SFA (\%) & -0.16 & -0.21 & -0.17 & -0.16 & -0.10 & -0.12 & -0.17 & -0.17 & -0.22 & $-0.26^{*}$ \\
\hline $\begin{array}{l}\text { Pedometer Steps } \\
\text { (steps/day) }\end{array}$ & 0.02 & -0.03 & 0.00 & 0.03 & 0.16 & 0.16 & 0.16 & 0.20 & 0.10 & 0.20 \\
\hline
\end{tabular}

Quality social support strategies defined as engaging a person other than themselves in a supportive activity. $\mathrm{kJ}-$ kilojoule; SFA - saturated fat. ${ }^{*} p<0.05$, ${ }^{* *} p<0.01,{ }^{* * *} p<0.001$ 
Table 5 Multiple linear regression of recording various Support Book components as predictors of weight loss (kg)

\begin{tabular}{|c|c|c|c|c|}
\hline \multirow[t]{2}{*}{ Weight change (kg) } & \multirow[t]{2}{*}{ Unadjusted model } & \multirow[b]{3}{*}{$p$-value } & \multicolumn{2}{|l|}{ Final model } \\
\hline & & & $\overline{R^{2}=0.37}$ & $p<0.001$ \\
\hline Variable & $\beta$-Coefficient $(95 \% \mathrm{Cl})$ & & $\beta$-Coefficient $(95 \% \mathrm{Cl})$ & $p$-value ${ }^{a}$ \\
\hline Goals (n) & $-0.40(-0.6,-0.2)$ & $<0.001$ & $-0.30(-0.6,-0.1)$ & 0.01 \\
\hline Rewards (n) & $-1.10(-1.8,-0.3)$ & 0.011 & & \\
\hline Social Support (n) & $-0.50(-0.9,-0.2)$ & 0.007 & & \\
\hline Weight Record (n) & $-0.40(-0.5,-0.3)$ & $<0.001$ & $-0.21(-0.39,-0.02)$ & 0.03 \\
\hline Food Diary Entries (n) & $-0.06(-0.09,-0.03)$ & $<0.001$ & & \\
\hline Pedometer Record (n) & $-0.30(-0.4,-0.1)$ & 0.001 & & \\
\hline Age (years) & $0.04(-0.05,0.12)$ & 0.389 & $0.02(-0.06,0.11)$ & 0.58 \\
\hline Socioeconomic Status & $0.01(-0.01,0.03)$ & 0.512 & $0.01(-0.01,0.03)$ & 0.21 \\
\hline Intervention (Online vs. Resources) & $1.60(-0.1,3.3)$ & 0.072 & $1.30(-0.3,2.9)$ & 0.11 \\
\hline
\end{tabular}

${ }^{\mathrm{a} B o l d e d} p$ value is statistically significant $(p<0.05)$.

weight loss, engagement in SCT-based tasks, or perception of program quality or program impact. The SHEDIT program was perceived to be supportive, enjoyable and beneficial.

A major finding of our study was the association found between various program tasks and behaviour change. While monitoring of all SCT-based tasks correlated with improved body composition, a multiple linear regression model demonstrated that goal setting and weekly monitoring of weight were the most important predictors of weight loss in this cohort of men. This model found that setting all nine goals equated to an additional weight loss of $2.9 \mathrm{~kg}$ and those who monitored their weight every week for the 3-month intervention had a corresponding additional weight loss of $2.7 \mathrm{~kg}$ compared with those who did not engage in these activities. This aligns with findings from a recent meta-regression of 122 physical activity and healthy eating behaviour change interventions, in which interventions with a self-monitoring component were significantly more effective than those without [27]. This finding also supports Bandura's notion within SCT that self-regulatory behaviours are an essential component of successful behaviour change. According to Bandura (1997), self-regulatory behaviours rise to become the most important component of behaviour change when the behaviour of interest involves skills that people already know or can quickly learn (e.g. the motor skills required to perform physical activity) [19].

Although goal setting was an important predictor of success, it is important to note that only half of the dietary and exercise goals the men recorded were considered 'SMART'. This is important as research has shown that setting SMART goals increases the likelihood of goal attainment whereas non-specific goals reduce selfefficacy, which has a negative impact on subsequent goal setting [28]. Despite explicit instructions and multiple examples, this finding suggests that men still have difficulty understanding SMART goals and will require additional support in future programs. It is plausible that men who were more ready to lose weight prior to commencing the study were more compliant with program activities, which may have created a spurious association between compliance and weight loss. However, a recent systematic review of goal setting and behaviour change in adults supported our finding, by demonstrating that goal setting leads to changes in dietary and exercise behaviours [28]. Similarly, regular self-weighing enables self-evaluation of progress and further reinforces desired behaviours, thus contributing to weight loss [28]. In addition, a number of recent papers have demonstrated that self-regulation is the most powerful construct within SCT to explain and predict physical activity behaviour [29-33], dietary behaviour $[30,34]$ and weight loss [35] across a variety of populations. Therefore, the current research supports our observation, suggesting an important role for both regular self-weighing and goal setting in promoting weight loss in men.

While, in general, men completed the designated SCT-based tasks, most did not document rewards for achieving their goals. Furthermore, the proportion of men engaging in this activity reduced by half between the first and third month of the intervention. The reason for this lack of reward documentation during the SHED-IT program is unclear, but may be because the participants did not find the activity helpful for weight loss, chose to keep the rewards to themselves, lost motivation over time, or had an initial lack of ideas for good rewards. Alternatively, some men may have viewed weight loss as the reward without needing to motivate themselves with additional extrinsic rewards. Interestingly, when men did set rewards, the 
Table 6 Participant perceptions of the SHED-IT program

\section{Overall Online Resources Online vs Resources}

$p$-value ${ }^{a}$

\section{The SHED-IT program}

a) SHED-IT provided me with the support needed to lose weight

$4.2 \pm 0.8 \quad 4.4 \pm 0.7 \quad 4.0 \pm 0.9 \quad<0.05$

b) The SHED-IT program corrected some wrong beliefs I had about physical activity, nutrition and weight loss

c) I now have a much better understanding of energy balance and weight loss

d) I would recommend SHED-IT to my friends

e) I would prefer being in a program that meets on the internet to being in one that meets in person

f) There was too much reading to do for the SHED-IT program

$4.0 \pm 0.9 \quad 3.9 \pm 1.0 \quad 4.1 \pm 0.7 \quad 0.51$

$4.3 \pm 0.6 \quad 4.3 \pm 0.7 \quad 4.3 \pm 0.6 \quad 0.86$

$4.6 \pm 0.6 \quad 4.7 \pm 0.5 \quad 4.5 \pm 0.6 \quad 0.32$

$2.8 \pm 1.2 \quad 3.0 \pm 1.2 \quad 2.5 \pm 1.2 \quad 0.08$

g) The Mathematics of Weight Loss was explained in a way that was easy to understand

$\begin{array}{llll}2.1 \pm 1.0 & 2.1 \pm 0.9 & 2.1 \pm 1.1 & 0.73 \\ 4.3 \pm 0.8 & 4.2 \pm 0.9 & 4.3 \pm 0.7 & 0.32\end{array}$

\section{SHED-IT Weight Loss DVD for Blokes}

a) The DVD helped me understand weight loss fundamentals

b) I found the DVD enjoyable to watch

c) The DVD helped me to lose weight

$\begin{array}{llll}4.3 \pm 0.6 & 4.2 \pm 0.6 & 4.3 \pm 0.6 & 0.34 \\ 4.2 \pm 0.7 & 4.2 \pm 0.7 & 4.2 \pm 0.7 & 0.68 \\ 3.8 \pm 0.8 & 3.8 \pm 0.8 & 3.8 \pm 0.8 & 0.83 \\ & & & \\ 3.9 \pm 0.8 & 3.9 \pm 0.6 & 4.0 \pm 0.9 & 0.43 \\ 4.1 \pm 0.8 & 4.1 \pm 0.5 & 4.2 \pm 0.9 & 0.87 \\ 4.0 \pm 0.8 & 3.9 \pm 0.8 & 4.1 \pm 0.8 & 0.31 \\ 3.9 \pm 1.1 & 3.6 \pm 0.8 & 4.3 \pm 1.0 & \mathbf{0 . 0 1 2} \\ & & & \\ 3.5 \pm 1.0 & 3.6 \pm 1.0 & 3.3 \pm 0.9 & 0.09 \\ & & & 0.12 \\ 3.3 \pm 1.0 & 3.4 \pm 1.0 & 3.1 \pm 0.9 & \\ & & & 0.28 \\ 2.9 \pm 0.9 & 3.1 \pm 0.9 & 2.9 \pm 0.8 & 0.64 \\ 2.9 \pm 0.9 & 2.9 \pm 1.0 & 2.8 \pm 1.0 & 0.60 \\ 4.1 \pm 0.8 & 4.1 \pm 0.9 & 4.2 \pm 0.8 & \end{array}$

\section{Other SHED-IT Weight Loss Resources}

a) The Weight Loss Handbook for Blokes was enjoyable to read

d) The SHED-IT Weight Loss Support Book for Blokes was easy to understand

e) The SHED-IT Weight Loss Support Book for Blokes helped me to lose weight

f) The Calorie, Fat and Carbohydrate Counter book helped me to choose which foods would eat while trying to lose weight

\section{Effect of SHED-IT on those around me}

a) As a result of my participation in SHED-IT, other members of my family have started to make healthier food choices

b) As a result of my participation in SHED-IT, other members of my family have become more active

c) As a result of my participation in SHED-IT other members of my family have lost weight

d) As a result of my participation in SHED-IT one or more of my friends have lost weight

e) I have had conversations with friends, co-workers and/or relatives about weight loss strategies I learned in SHED-IT

\section{Calorie King Website}

a) The Calorie King website was easy to understand

b) Recording my daily food and exercise on the Calorie King website was time consuming

c) The Calorie King website was a valuable tool to help me understand how to lose weight

d) The Calorie King User Guide was useful

e) The Calorie King User Guide was easy to follow

\section{Feedback}

a) I found the email feedback reports provided by the SHED-IT team helped me to lose weight

b) The feedback reports were personalised enough

c) I would have preferred fewer email feedback reports from the SHED-IT team

d) I would have preferred more email feedback reports from the SHED-IT team

51

86

32

Data reported as mean \pm standard deviation of participant responses to the statements above, where: $1=$ strongly disagree; 2 = disagree; $3=$ neutral; 4 = agree; $5=$ strongly agree. $P$-values are given for the interaction and main effects of intervention group and compliance. Program compliance is defined as returning the

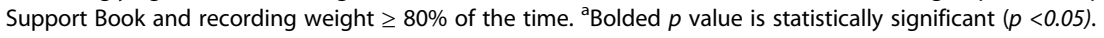


majority involved going out for dinner, drinking alcohol, or having a night out. This supports previous research demonstrating that men value weight loss programs that are not overly restrictive [36], and that allow them to socialise and enjoy energy-dense luxuries on occasion [10].

Overall, most men did not engage with the social support task in the Support Book. Less than 25\% of men recorded strategies to engage social networks, and one-third of these were deemed to be poor quality because they recorded themselves as their support person rather than other people. Although the reason for the poor uptake of this activity is not known, it is possible that its importance was not sufficiently emphasised, that the activity was not well understood, or that the men's previous exposure to this style of documentation or thinking was limited. In addition, sociological literature on men's health shows that men prefer to engage in lifestyle programs that they can complete independently [37], and thus the men may not have valued the idea of asking for help or support. Despite this, social support has been found to increase both intervention compliance and weight loss $[38,39]$. As such, identifying strategies that improve compliance with this activity may be warranted. It is also important to note that social support is not the only socio-structural factor outlined in Bandura's SCT. However, targeting and operationalising this construct remains a difficult task as it represents a multitude of factors above and beyond social support networks [40]. These include ethnic group membership, education and intelligence, socio-economic status, the built environment and access to local facilities [41]. To improve study outcomes, future studies should explore novel ways to operationalise this construct above engaging social support networks alone.

Compliance or adherence to program tasks has been acknowledged as a major limitation of weight loss interventions, with the Internet as an engagement medium being identified as a particular risk. Indeed, attrition rates have been reported to exceed $40 \%$ for internet-based weight loss research [42]. Despite this, the current study had an attrition rate of only $20 \%$ for both intervention groups, which is similar to the average attrition rate of $21 \%$ for weight loss interventions in general. This suggests that, despite having no face-to-face contact, SHED-IT is as effective as other weight loss program formats in men. In addition, this is supported by our findings that overall weight loss, program engagement, perception of program quality, and program impact were similar for both the online self-monitoring and paper-based self-monitoring versions of SHED-IT.

A significant strength of the SHED-IT weight loss community program was its theoretical structure. Most weight loss interventions are not theory-driven, or use theory only as a loose framework, which is known to weaken the intervention effects [43]. As noted previously, the SHED-
IT program was informed by Bandura's SCT and was constructed to explicitly target the key behaviour change mediators specified in the theory. A systematic review of studies using the Internet as a medium for delivering health behaviour change programs demonstrated that, while only $20 \%$ of interventions used or mentioned theory as an intervention technique, a greater use of theory improved effect sizes, particularly those extensively incorporating theory into their program [43]. This review also demonstrated that goal setting, self-monitoring, social support and reward provision all have a significant, positive influence on behaviour change [43]. While all SCTbased tasks correlated with improved body composition in the current study, goal setting and weight monitoring were the strongest predictors of weight loss. Therefore, the combination of SCT-tasks used in this study improved weight outcomes in men.

Overall, men found the program to be beneficial and to provide sufficient support for their weight loss endeavours. Of particular interest, the men reported that the DVD was enjoyable to watch, improved their understanding of how to lose weight and approximately onethird of men watched the DVD more than once. These are important findings, given that the DVD was introduced to improve the scalability of the intervention by replacing the face-to-face information session of the pilot study [13]. Of note, both groups reported similar engagement with the program and both groups indicated that they would recommend SHED-IT to a friend, suggesting that the online self-monitoring and paper-based self-monitoring versions of SHED-IT were equally effective in engaging men. Interestingly, compliance with exercise monitoring was greater for the Online group compared to the Resources group. Although this may have been a chance finding due to the number of comparisons tested, it may also have been a function of taskdifficulty. The online exercise diaries utilised established exercise databases and automatically calculated kilojoules burned during exercise, which eliminated the need to perform time-consuming calculations [44]. Therefore, the findings of the current process evaluation support the use of the Internet as an effective medium for weight loss intervention in men and suggest further examination is warranted.

A limitation of this study is some participants did not return their Support Book and the extent to which these were completed cannot be determined. However, the overall retention of participants in the trial was strong [9]. In addition, this study cannot confirm whether completion of the Support Book resulted in greater weight loss, because the Support Books were collected immediately prior to the assessment and not monitored throughout the intervention period. This could be investigated in future trials. This study contained several strengths including recruitment of 
a community sample of men, comprehensive tailoring of intervention materials to appeal to men and use of an extensively validated behaviour change theory. Aside from assessments, the SHED-IT programs involved no face-toface contact and were considerably lower in intervention intensity than previous male-only weight loss studies [9]. The current analyses allowed for a comprehensive process evaluation, which provides valuable information to inform the development of novel obesity treatment strategies that engage men.

Currently, there is a dearth of research regarding how to engage men in weight loss programs and how to create effective programs that are tailored to their interests. Although we have previously established the efficacy [13] and effectiveness [17] of the SHED-IT program, this was the first study to determine which program components were most strongly associated with success. In addition to informing future refinements of the program, the current findings may help to encourage and inform other weight loss interventions for men, which are urgently required $[5,9]$. In summary, based on the findings of the current process evaluation, we make the following recommendations for the development of such interventions:

1. Face-to-face information sessions or tailored intervention components may not be required for men to feel sufficiently supported in weight loss programs. Despite being considerably lower in intensity than other programs, men felt that the Online and Resources-only modalities provided them with sufficient support to lose weight.

2. The quality of strategies (e.g. gender tailoring selection of behaviour change techniques,) and information in the resources may be more important for men than a particular treatment modality. Both the Online and Resources groups were equally satisfied with the program and would have recommended the program to their friends.

3. Goal setting and weekly weight tracking were found to be the key program components associated with success for men.

4. Men may require additional information, examples or strategies to be able to successfully set S.M.A.R.T. goals, particularly for dietary and physical activity behaviours.

5. Future studies should pay attention to men's initial weight loss expectations, particularly in the context of setting goals. Initially, approximately $25 \%$ of men who set a weight-related goal were aiming to lose more than the recommended $1 / 2$ to $1 \mathrm{~kg}$ per week and $33 \%$ of men did not achieve their first target.

6. Despite being key behaviour change strategies outlined in Bandura's SCT $[18,40]$, setting social support strategies and rewards for success were not associated with improved treatment outcomes for men. However, it is important to note that men experienced considerable conceptual confusion with the social support task, with approximately $50 \%$ of men listing themselves as their own social support.

7. For men, physical activity goals were predominantly related to accessible lifestyle activities such as walking/ increasing step counts. Future studies with men should include a strong focus on these activities, which do not require specialised knowledge or skills.

8. When trying to improve eating habits, the most common goal for men was to reduce junk food intake, particularly in the first month. Given the large proportion of men's energy intake that comes from non-essential foods [45], this is an important finding and these goals could be encouraged in future programs

\section{Conclusion}

Given the increasing prevalence of overweight and obesity in men and the lack of targeted weight loss interventions conducted in this population, the design and evaluation of effective and acceptable programs is imperative. There is a need for appealing and widely accessible programs for men and this process evaluation provides strong direction for the design of such trials. This study demonstrates that Bandura's SCT provides a useful framework to design weight loss interventions for men, and future studies should include a strong focus on self-regulatory behaviours such as self-monitoring and goal setting to enhance behaviour changes and improve treatment effects. Further investigation into the value that men place on social support during weight loss is warranted, with most men in the current study not complying with this aspect of the program. Overall, SHED-IT provides an effective medium for delivering a weight loss program tailored to men's preferences.

\section{Additional file}

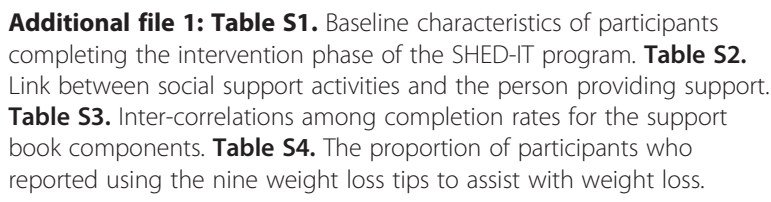

\section{Abbreviations}

BMI: Body Mass Index; RCT: Randomised Controlled Trial; SCT: Social

Cognitive Theory; SES: Socio-economic status; SHED-IT: Self-help, Exercise and Diet using Information Technology; SMART: Specific, measurable, attractive, realistic, time-targeted.

\section{Competing interests}

The authors declare that they have no competing interests. 


\section{Authors' contributions}

PJM, RC, CEC, RCP were responsible for identifying the research questions, design of the study, obtaining ethics approval, the acquisition of funding and overseeing study implementation. MDY contributed to development of intervention materials, recruiting participants and study implementation. HAS completed the statistical analysis for the current study. All authors were responsible for the drafting of this manuscript and have read and approved the final version.

\section{Acknowledgements}

The SHED-IT RCT is funded by a National Heart Foundation Grant-in-Aid (2010-2011). We would like to thank the participating men, Elroy Aguiar, James Dower, Bryana Melnik, Dana Williams, Alyce Cook, Trish Robson, Bronwyn Berthon, Ashlee Lucas, Roberta Asher, Sarah Costigan, Peter Nelson, Alecia Greig, Christine Young, Charlotte Bull, Amanda Williams, Erin Paul, Lachlan Collins, John Chambers and Glenys Chambers. The authors thank Professor Graham Giles of the Cancer Epidemiology Centre of the Cancer Council Victoria for permission to use the Dietary Questionnaire for Epidemiological Studies (Version 2), Melbourne: The Cancer Council Victoria, 1996. RCP is funded by a Senior Research Fellowship from the National Health and Medical Research Council of Australia. CEC is funded by a Career Development Award from the National Health and Medical Research Council of Australia.

\section{Author details}

'Priority Research Centre in Physical Activity and Nutrition, The University of Newcastle, Callaghan 2308, NSW, Australia. ${ }^{2}$ School of Education, Faculty of Education and Arts, The University of Newcastle, Callaghan 2308, NSW, Australia. ${ }^{3}$ Nutrition and Dietetics, School of Health Sciences, Faculty of Health and Medicine, The University of Newcastle, Callaghan 2308, NSW, Australia. ${ }^{4}$ School of Biomedical Sciences and Pharmacy, Faculty of Health and Medicine, The University of Newcastle, Callaghan 2308, NSW, Australia.

Received: 26 November 2013 Accepted: 27 June 2014

Published online: 11 July 2014

\section{References}

1. Finucane MM, Stevens GA, Cowan MJ, Danaei G, Lin JK, Paciorek CJ, Singh GM, Gutierrez HR, Lu Y, Bahalim AN, Farzadfar F, Riley LM, Ezzati M: National, regional, and global trends in body-mass index since 1980: systematic analysis of health examination surveys and epidemiological studies with 960 country-years and 9.1 million participants. Lancet 2011, 377(9765):557-567.

2. World Health Organization: Obesity: preventing and managing the global epidemic. Geneva: Report of a WHO Consultation; 2000.

3. Beuther DA, Sutherland ER: Overweight, obesity, and incident asthma: a meta-analysis of prospective epidemiologic studies. Am J Respir Crit Care Med 2007, 175:661-666.

4. Lemon SC, Rosal MC, Zapka J, Borg A, Andersen V: Contributions of weight perceptions to weight loss attempts: differences by body mass index and gender. Body Image 2009, 6(2):90-96.

5. Pagoto SL, Schneider KL, Oleski JL, Luciani JM, Bodenlos JS, Whited MC: Male inclusion in randomized controlled trials of lifestyle weight loss interventions. Obesity 2012, 20(6):1234-1239.

6. Sabinsky MS, Toft U, Raben A, Holm L: Overweight men's motivations and perceived barriers towards weight loss. Eur J Clin Nutr 2007, 61:526-531.

7. Sherwood NE, Morton N, Jeffery RW, French SA, Neumark-Sztainer D, Falkner $\mathrm{NH}$ : Consumer preferences in format and type of community-based weight control programs. Am J Health Promot 1998, 13:12-18.

8. Wolfe BL, Smith JE: Different strokes for different folks: Why overweight Men Do Not seek weight loss treatment. Eat Disord 2002, 10:115-124.

9. Young MD, Morgan PJ, Plotnikoff RC, Callister R, Collins CE: Effectiveness of male-only weight loss and weight loss maintenance interventions: a systematic review with meta-analysis. Obes Rev 2012, 13(5):393-408.

10. Morgan PJ, Warren JM, Lubans DR, Collins CE, Callister R: Engaging men in weight loss: experiences of men who participated in the male only SHED-IT pilot study. Obes Res Clin Pract 2011, 5(3):e239-e248.

11. Morgan PJ, Lubans DR, Collins CE, Warren JM, Callister R: 12-month outcomes and process evaluation of the SHED-IT RCT: an internet-based weight loss program targeting men. Obesity 2011, 19(1):142-151.
12. Oakley A, Strange V, Bonell C, Allen E, Stephenson J: Process evaluation in randomised controlled trials of complex interventions. Br Med J 2006, 332:413-416.

13. Morgan PJ, Lubans DR, Collins CE, Warren JM, Callister R: The SHED-IT randomized controlled trial: evaluation of an internet-based weight-loss program for men. Obesity 2009, 17(11):2025-2032.

14. Collins CE, Morgan PJ, Warren JM, Lubans DR, Callister R: Men participating in a weight-loss intervention are able to implement key dietary messages, but not those relating to vegetables or alcohol: the self-help, exercise and diet using internet technology (SHED-IT) study. Public Health Nutr 2011, 14(1):168-175

15. Lubans DR, Morgan PJ, Collins CE, Warren JM, Callister R: Exploring the mechanisms of weight loss in the SHED-IT intervention for overweight men: a mediation analysis. Int J Behav Nutr Phys Act 2009, 6(76):1-8.

16. Morgan PJ, Collins CE, Plotnikoff RC, McElduff P, Burrows T, Warren JM Young MD, Berry N, Saunders KL, Aguiar EJ, Callister R: The SHED-IT community trial study protocol: a randomised controlled trial of weight loss programs for overweight and obese men. BMC Public Health 2010 10(701):1-11.

17. Morgan PJ, Callister R, Collins CE, Plotnikoff RC, Young MD, Berry N, McElduff P, Burrows T, Aguiar EJ: The SHED-IT community trial: a randomized controlled trial of internet- and paper-based weight loss programs tailored for overweight and obese men. Ann Behav Med 2013, 45(2):139-152.

18. Bandura A: Social foundations of thought and action: a social cognitive theory. Englewood Cliffs, NJ: Prentice-Hall; 1986.

19. Bandura A: Self-efficacy: The exercise of control. New York, NY: W.H. Freeman; 1997.

20. World Health Organization (WHO): Waist circumference and waist-hip ratio: report of a WHO expert consultation. Geneva, Switzerland: WHO; 2008.

21. Gibson AL, Holmes JC, Desautels RL, Edmonds LB, Nuudi L: Ability of new octapolar bioimpedance spectroscopy analyzers to predict 4component-model percentage body fat in Hispanic, black, and white adults. Am J Clin Nutr 2008, 87(2):332-338

22. Australian Bureau of Statistics: Socio-economic indexes for areas (SEIFA) Australia- 2006: postal areas, index of relative socio-economic advantage and disadvantage. Canberra: Commonwealth of Australia; 2008. ABS catalogue 2033.0.55.001.

23. Collins CE, Boggess MM, Watson JF, Guest M, Duncanson K, Pezdirc K, Rollo M, Hutchesson MJ, Burrows T: Reproducibility and comparative validity of a food frequency questionnaire for adults. Clin Nutr. In press; Accepted September, 2013.

24. Baum CL II, Ruhm CJ: Age, socioeconomic status and obesity growth. $J$ Health Econ 2009, 28:635-648.

25. Morgan PJ, Lubans DR, Callister R, Okely AD, Burrows TL, Fletcher R, Collins CE: The 'healthy dads, healthy Kids' randomized controlled trial: efficacy of a healthy lifestyle program for overweight fathers and their children. Int J Obes 2011, 35(3):436-447.

26. Morgan PJ, Collins CE, Plotnikoff RC, Callister R, Burrows T, Fletcher R, Okely $A D$, Young MD, Miller A, Lloyd AB, Cook AT, Cruickshank J, Saunders KL, Lubans DR: The 'Healthy Dads, Healthy Kids' community randomized controlled trial: A community-based healthy lifestyle program for fathers and their children. Preventive Medicine 2014, 61:90-99.

27. Michie S, Abraham C, Whittington C, McAteer J, Gupta S: Effective techniques in healthy eating and physical activity interventions: a meta-regression. Health Psychol 2009, 28(6):690-701.

28. Pearson ES: Goal setting as a health behavior change strategy in overweight and obese adults: a systematic literature review examining intervention components. Patient Educ Couns 2012, 87:32-42.

29. Anderson ES, Wojcik JR, Winett RA, Williams DM: Social-cognitive determinants of physical activity: The influence of social support, self-efficacy, outcome expectations, and self-regulation among participants in a church-based health promotion study. Health Psychol 2006, 25(4):510-520

30. Anderson-Bill ES, Winett RA, Wojcik JR: Social cognitive determinants of nutrition and physical activity among Web-health users enrolling in an online intervention: the influence of social support, self-efficacy, outcome expectations, and self-regulation. J Med Internet Res 2011, 13(1):19-19.

31. Anderson-Bill ES, Winett RA, Wojcik JR, Williams DM: Aging and the social cognitive determinants of physical activity behavior and behavior change: evidence from the guide to health trial. J Aging Res 2011, 2011:1-11. 
32. Ayotte BJ, Margrett JA, Hicks-Patrick J: Physical activity in middle-aged and young-old adults: the roles of self-efficacy, barriers, outcome expectancies, self-regulatory behaviors and social support. J Health Psychol 2010, 15(2):173-185

33. Dlugonski D, Wojcicki TR, McAuley E, Motl R: Social cognitive correlates of physical activity in inactive adults with multiple sclerosis. Int I Rehabil Res 2011, 34(2):115-120.

34. Anderson ES, Winett RA, Wojcik JR: Self-regulation, self-efficacy, outcome expectations, and social support: social cognitive theory and nutrition behavior. Ann Behav Med 2007, 34(3):304-312.

35. Anderson-Bill ES, Winett RA, Wojcik JR, Winett SG: Web-based guide to health: relationship of theoretical variables to change in physical activity, nutrition and weight at 16-months. J Med Internet Res 2011, 13(1):28-28.

36. Egger G: Intervening in men's nutrition: lessons from the GutBuster men's 'waist loss' program. Aust J Nutr Diet 2000, 57(1):46-49.

37. Lewis S, Thomas SL, Hyde J, Castle DJ, Komesaroff PA: A qualitative investigation of obese men's experiences with their weight. Am J Health Behav Jul 2011, 35(4):458-469.

38. McConnon A, Kirk SFL, Ransley JK: Process evaluation of an internet-based resource for weight control: Use and views of an obese sample. J Nutr Educ Behav 2009, 41(4):261-267.

39. Livhits M, Mercado C, Yermilov I, Parikh JA, Dutson E, Mehran A, Ko CY, Shekelle PG, Gibbons MM: Is social support associated with greater weight loss after bariatric surgery? A systematic review. Obes Rev 2011, 12(2):142-148

40. Bandura A: Health promotion by social cognitive means. Health Educ Behav Apr 2004, 31(2):143-164.

41. Luszczynska A, Schwarzer R: Social cognitive theory. In Predicting health behavior. Edited by Connor M, Norman P. New York, NY: McGraw Hill International; 2005

42. Neve M, Morgan PJ, Jones PR, Collins CE: Effectiveness of web-based interventions in achieving weight loss and weight loss maintenance in overweight and obese adults: a systematic review with meta-analysis. Obes Rev 2010, 11(4):306-321

43. Webb TL, Joseph J, Yardley L, Michie S: Using the internet to promote health behavior change: a systematic review and meta-analysis of the impact of theoretical basis, Use of behavior change techniques, and mode of delivery on efficacy. J Med Internet Res 2010, 12(1):e4.

44. Burke LA, Wang J, Sevick MA: Self-monitoring in weight loss: a systematic review of the literature. J Am Diet Assoc 2011, 111:92-102.

45. Blomfield RL, Collins CE, Hutchesson MJ, Young MD, Callister R, Morgan PJ: Impact of self-help weight loss resources with or without online support on the dietary intake of overweight and obese men: the SHED-IT randomised controlled trial. Obes Res Clin Pract. in press.

doi:10.1186/s12966-014-0089-9

Cite this article as: Morgan et al:: Associations between program outcomes and adherence to Social Cognitive Theory tasks: process evaluation of the SHED-IT community weight loss trial for men. International Journal of Behavioral Nutrition and Physical Activity 2014 11:89.

\section{Submit your next manuscript to BioMed Central and take full advantage of:}

- Convenient online submission

- Thorough peer review

- No space constraints or color figure charges

- Immediate publication on acceptance

- Inclusion in PubMed, CAS, Scopus and Google Scholar

- Research which is freely available for redistribution

Submit your manuscript at www.biomedcentral.com/submit
C Biomed Central 